Notfall Rettungsmed $2013 \cdot 16: 508-511$

DOI 10.1007/s10049-013-1761-3

(C) Springer-Verlag Berlin Heidelberg 2013

\author{
L. Bossaert ${ }^{1} \cdot$ D. Chamberlain ${ }^{2}$ \\ ${ }^{1}$ Boechout \\ 2 Hove
}

\title{
The European Resuscitation Council
}

\section{Its history and development}

This year, the European Resuscitation Council (ERC) celebrates its 25th anniversary. The ERC was created by a small group of friends and has developed in to a professional organization with in ternational recognition, dealing with all aspects of resuscitation care in Europe. These 25 years have formed a substantial and exciting part of the professional lifetime of the present authors, who have had the privilege of participating in the conception, the birth, and the development of the Council.

All official documents, printed materials, reports, and minutes are carefully preserved, but it is also important to record the early history of the ERC before memories begin to fade: how and why was the ERC started and what can we learn from successes and failures? In 1991 John McCabe and Douglas Chamberlain introduced the ERC in editorials in Resuscitation, shortly after it became the official journal of the organization $[1,2]$.The history of the first half of its life appears on the ERC website at www.erc.edu. The 25th anniversary is an appropriate occasion to update these earlier reviews.

\section{Europe: the past}

Europe has always been a fertile soil for cardiopulmonary resuscitation (CPR) and emergency medical care. One has only to consider the Humane Societies that were set up in Amsterdam (1767), London (1774), and Paris (1792). Bloody wars on the European continent (as in North America) stimulated the establishment of ambulance and emergency medical services for military and for civilians, and later also nongovernmental volunteer first aid organisations such as the Red Cross and the Orders of Malta, St Andrews, and St John. Europe has produced many of the true pioneers of resuscitation science: Vladimir Negovsky, Peter Safar, and also Fritz Ahnefeld who introduced the universal concept of the Chain of Survival ("die Rettungskette") [3]. European research has significantly influenced the management of sudden death and the frequently underlying acute coronary syndrome: defibrillation (JL Prévost and F Batelli, Geneva 1899), prehospital cardiac care (Frank Pantridge, Belfast 1965), coronary angioplasty (Andreas Gruntzig 1975), therapeutic hypothermia, and the introduction of many drugs such as $\beta$-blockers, calcium antagonists, aspirin, fibrinolytics, and antiarrhythmics. These all underwent further development within international organisations worldwide [4].

In the 1980s, Europe was developing both in political and economic terms and the desire for collaboration was building up rapidly. The Council of Europe was established in 1947, followed in 1993 by the European Union that has grown from 6 to 28 member countries. The euro followed in 1999 and the European Central Bank in 2002. Today, however, we see that Foucault's pendulum is swinging back from enthusiasm for international collaboration to a renewed emphasis on national interest. This change in political attitude is also reflected in the functioning of European and national professional and scientific organisations.

\section{Developments in CPR}

In 1960, the description of chest compression by W Kouwenhoven, D Jude and G Knickerbocker led to the development of CPR that was recognised as a composite entity at a meeting in Maryland shortly afterwards [5]. By 1966, the techniques were adopted internationally, with the recommendation that healthcare professions should receive appropriate training. The American Heart Association (AHA) played a key role in the process. The AHA Standards and Guidelines for CPR (1974, 1980 and 1986) were published in JAMA and became the international gold standard for CPR for the next 2 decades.

In many other countries, national CPR councils or working groups were established including the Resuscitation Council (UK), a CPR working group of the Swedish Cardiac Society, a CPCR working group of the Belgian Society for Intensive Care, the Beirat for Wiederbelebung of the German Medical Council, and the Institute of Reanimatology in Moscow. It became clear that the time was ready for international European collaboration in this area. In 1986, Lars Mogensen and one of the current authors proposed that the European Society of Cardiology (ESC) should create a working group for $\mathrm{CPR}$ [6]. It received support from the Council but was rejected by the General Assembly.

This article was published in Resuscitation, Volume 84 (2013):1291-1294; Leo Bossaert and Douglas Chamberlain, 'The European Resuscitation Council: its history and development'. Copyright European Resuscitation Council 2013. 
The proposers of the initiative were disappointed, but they remembered that every defeat is also an opportunity-and so a new initiative was taken.

\section{Foundation of the ERC}

In August 1988, following the adverse decision at the ESC Congress of Cardiology in Vienna, a group of dedicated cardiologists met in the catering area of the congress. Fortified by a beer and a hamburger, Douglas Chamberlain, Leo Bossaert, Lars Mogensen, Hugh Tunstall-Pedoe, Paul Hugenholtz, Stig Holmberg and John Camm agreed that it was time to bring together European individuals, organisations, and societies having an interest in resuscitation medicine with the intention of setting up a multidisciplinary collaboration. The name European Resuscitation Council (ERC) was selected for the new group. Agreement was reached to set up a meeting with representatives of all major European disciplines involved, which took place in Antwerp on 13 December 1988. The initial meetings were supported by a grant from the Laerdal Foundation for Acute Medicine.

The members at the founding meeting of the ERC on 13 December 1988 included all of those mentioned above and also P. Baskett (UK), H. Delooz (B), E. Edgren (S), T. Evans (UK), N. Hart (NL), S. Holmberg (SE), R. Juchems (DE), A. Marsden (UK), A. Mullie (BE), E. Sandoe (DK), D. Scheidegger (CH), D. Zideman (UK), C. Moffat (UK) and N. Perales (ES) as a Steering Committee. Douglas Chamberlain was elected as temporary Chairman and Leo Bossaert as temporary Secretary until official elections could take place.

The objectives were set as follows:

To save human life by improving standards of resuscitation in Europe, and by coordinating the activities of European organisations with a legitimate interest in cardiopulmonary resuscitation.

This was to be achieved by producing guidelines and recommendations, designing and implementing teaching programmes, monitoring and auditing of CPR practice, promoting awareness and science and organising scientific meet- ings. In August 1989 the Steering Committee became the first Executive Committee with official representation from the ESC, the European Academy of Anaesthesiology, and the European Society for Intensive Care Medicine.

Peter Baskett was the first elected Chairman (succeeded in later years by Wolfgang Dick, Pierre Carli, Petter Andreas Steen, David Zideman, Bernd Boettiger, and Maaret Castren). Stig Holmberg became vice-chairman, Daniel Scheidegger was Honorary Treasurer (succeeded by Dietrich Kettler, Jan Bahr, and Tony Handley), with Leo Bossaert as Honorary Secretary (succeeded by Koen Monsieurs and Dominique Biarent). Douglas Chamberlain succeeded John McCabe as Editorin-Chief of the Journal, followed by Peter Baskett and Jerry Nolan. An affiliation with AHA and Resuscitation Councils of Australia, New Zealand, Southern Africa and Japan, contributed to the international recognition of Resuscitation as the leading journal in this domain.

The first General Assembly took place in June 1990 in Amsterdam where the first statutes were approved. Working groups in Basic Life Support (BLS), Advanced Life Support (ALS), Paediatric Life Support (PLS), Research, TechnicalProfessional Liaison, Research coordination, Training \& Education were initiated and started preparing ERC Guidelines and Courses. The composition of the working groups was adjusted from time to time. Separate structures were created for courses and guidelines, with care to protect the appropriate relationship between them. Other types of core business of the ERC were grouped into domains. This structure formed the basis for the ERC Strategic plans. The mission statement and the objectives of the ERC have remained virtually unchanged over the past 25 years. Encompassing the network of National Resuscitation Councils (NRCs) in Europe, the mission statement may now stated very simply:

To preserve life by making high quality resuscitation available to all.

\section{Organisation}

The 1992 statutes ensured that the initial group of friends became an organised group of friends. Its origins had given the ERC a specific style and charm of one big family. Many of the successes and achievements were facilitated by this personal approach and by the commitment of individual members that were driven by passion and commitment. We had early leaders of the kind that were needed for setting the newly born ERC on the right track: we did not need too many words to have a concept accepted and we did not need too much debate for it to be implemented and put into operation. Separate statutes were created for the Secretariat, which was in charge of the operational activities and served as a financial and legal entity with Leo Bossaert as Executive Director. This double structure seemed operationally necessary at the time, but had several disadvantages and created confusion.

The close-knit "structure of friends" could not be maintained as the organisation grew at a very rapid pace to more than 1000 members in 29 affiliated NRCs. It now has major biennial congresses, dozens of course manuals translated into most European languages, hundreds of courses, and now thousands of certified instructors needing communication via a course management system (CMS), website, and newsletters. This requires a professional organisation supported by a strong central office, initially with one individual employed part-time but now staffed by 5.5 full-time equivalent employees. Activities have been more and more regulated by legal obligations with external support required for fis$\mathrm{cal}$, financial and legal matters, and also for informatics and graphic design. In 2011, the structure of the ERC was modernised further in accordance with legislation on nonprofit organisations, with clear definitions relating to the General Assembly, Executive Committee, Board, General Purpose Committee, and with a $\mathrm{CEO}$ replacing the Executive Director and Business Manager. The statutes need more changes in 2013 in line with modern organisational principles, based on corporate governance, efficiency and subsidiarity.

Collaboration with industrial partners was encouraged from the beginning 
in 1988. Patron membership had been included in the original statutes. Business partners (BP) recognize the importance of the ERC for many reasons. They understand the influence of the ERC leadership, they know the number of ERC members (including the associate membership) and congress participants, and are aware of the impact of ERC guidelines on practice in Europe. There is a shared scientific and commercial interest in CPR-related products. Interaction with BPs is recognised as a delicate balance between mutual benefit and conflict of interest within a non-profit organisation. Recently, a code of ethical conduct was approved and was welcomed as a helpful framework for the interaction between members of ERC and industrial partners.

\section{Congresses}

The first Congress of the ERC was in Brighton in 1992 and was hosted by the Resuscitation Council (UK). American and Australian colleagues were invited. The move to wider international cooperation that had been proposed by the AHA at a meeting in Dallas in 1991 was thus strengthened, and a liaison committee that later became known as ILCOR was established formally at this ERC conference. The event in Brighton was a major success and was followed at intervals of 2 years by congresses in Mainz, Seville, Copenhagen, Antwerp, Firenze, Budapest, Stavanger, Ghent, Porto, Vienna, with Bilbao planned for 2014. Attendances grew to over 1000 participants from healthcare professionals from all European countries and many other parts of the world. Symposia on specific topics were organised for the intervening years in Lyon, Marseille, Cologne, Malta, with Krakow next in line. The collaboration with the NRCs in the organisation of the congresses produces benefit for all and continues to evolve. The content and style of the congress strikes a balance between interest in any new guidelines and attention to on-going research, education, implementation and communication involving scientists, healthcare professionals, instructors and the community at large. Today congresses are managed by a permanent Organising Committee that must pay proper regard to economic and social realities.

\section{The ERC guidelines}

In 1992, the ERC presented Guidelines for BLS [8] and ALS at its first Congress in Brighton. In 1994, Guidelines for PLS [10] and Guidelines for the Management of Peri-arrest Arrhythmias [11] followed at the second Congress in Mainz, with Guidelines for the Basic and Advanced Management of the Airway and Ventilation during Resuscitation at the third Congress in Seville in 1996 [12], and updated Guidelines at the 4th Scientific Congress of the ERC in Copenhagen in 1998 [13]. After this period, Guidelines have been produced at a frequency of about every 5 years: 2000 (but with an update in 2001), 2005, and 2010 as discussed by Nolan [14]. Those for 2015 are now in preparation. ERC guidelines and national derivatives are now accepted throughout most of Europe as the standard of care and the reference for clinical practice.

Participation in this international scientific network under the auspices of ILCOR is recognised as one of the strengths of the ERC. As a result, science is now being reviewed globally with a consensus on science that serves as a foundation from which the ERC, the AHA, and equivalent organizations can produce guidelines according to the specific needs of their regions $[15,16]$. This brings us closer to the goal of uniform CPR practice. But there remains still a long way to go to achieve this uniformity.

\section{The ERC courses}

The goal of uniform CPR practice across Europe cannot be achieved without uniform education. In 1989 the question was asked:

If the science is the same why don't we teach the same?

The ERC courses were the answer: uniform content reflecting most recent guidelines, uniform course organisation with emphasis on hands-on training, uniform teaching methods according to the 4-step learning principle, quality control, certification, professional management. The initial working groups developed the first course manuals and trained the first instructors. For updating and developing the courses, international course committees and educational master-classes were introduced. The cascade principle worked well, and in a short time many thousands were trained: school children, students, citizens, ambulance crew, rescuers, doctors and nurses. To support this network and to facilitate quality control, an expert online Course Management System (CMS) was developed. With the support of NRCs, manuals were translated into many European languages. Because of these uniform courses, it is now realistic for instructors from all parts of Europe to meet for no more than a few minutes before running matching programmes in BLS, ALS, PLS, Neonatal Life Support, or European Trauma Course (ETC).

After the publication of the new guidelines in 2015, the courses will be updated.

It is a major challenge for the ERC to update not only the content of the courses but to adjust the format, the materials, illustrations, and methods that match current perceptions and practices. This requires close collaboration with our stakeholders: the NRCs, the professional societies, and governmental authorities for health and education on a National and European level. This helps to ensure that the ERC courses retain their attraction as well as uniformity. We have done it before and can continue to do it!

\section{Interprofessional and international collaboration}

Guidelines, courses, congresses, quality of care, research and awareness are specified by ERC statutes as the core business, in keeping with its mission statement. Interprofessional collaboration is the modus operandi for reaching these objectives, by promoting and strengthening the network of NRCs in Europe and by promoting exchange between different healthcare professional disciplines. The ERC was founded originally with the support of existing professional organisations: representatives of the European Societies of Cardiology, Anaesthesia, Intensive Care, and Emergency Medicine; the European Red Cross, Nursing, and First Aid organizations soon became involved. The collaboration with these societies has been re- 
flected in membership of the Executive Committee and the General Assembly, and by joint contributions in congresses on topics such as heart attack [17], AEDs [18], post-resuscitation care [19], trauma [20], and also laboratory research [22]. The ETC is also an indication of the importance of interprofessional collaboration [22]. The ERC has played a major part in the creation and development of the Utstein system for uniform reporting, which has been crucial to permitting meaningful comparisons between EMS systems and to improving the quality of epidemiological studies relating to cardiac arrest $[23,24]$. Other examples of collaborative ventures include the EuReCa project [25], research on EMS dispatch times, and initiatives on the training of school children. There is need, however, to be mindful at all times of the potential for tensions that can come from cooperation between our over-arching international Council and the local member organization-with a continuing need for mutual recognition of the expertise and effort essential for collaborative ventures.

The NRCs can, indeed, be regarded as a fundamental operational mechanism of the ERC as is recorded in its byelaws that include a recommendation for collaboration being formalised by a Memorandum of Understanding or other appropriate agreement. This has been achieved with no less than 29 countries, including some in North Africa and in the Middle East.

One outstanding result of pressure at European and local levels occurred in June 2012 when 359 members of the European Parliament carried a majority vote that recommended an increased awareness of cardiac arrest in Europe and encouraged member countries to take appropriate action to implement common training in the use of AEDs in the community, to make any necessary amendments in legislation to facilitate CPR and defibrillation by lay responders, and to initiate quality management of these programmes [26]. A European awareness day is due to be initiated on 16 October 2013, to be known as Restart a Heart Day. This strong endorsement by the European Parliament and by the European Health Commissioner of the objectives of the ERC is an achievement that should please all our members,
NRCs and individuals, and stimulate continuing enthusiasm and progress. We still have much to do before we can feel that everything possible has been done to save human life by improving standards of resuscitation in Europe.

\section{Leo Bossaert}

\section{Douglas Chamberlain}

\section{Corresponding address}

\section{Bossaert}

Boechout

Belgium

leo.bossaert@gmail.com

\section{Compliance with ethical guidelines}

Conflict of interest. L. Bossaert and D. Chamberlain state that there are no conflicts of interest.

The accompanying manuscript does not include studies on humans or animals.

\section{References}

1. McCabe J (1991) Editorial note. Resuscitation 21:1-5

2. Chamberlain D (1992) Editorial. Resuscitation 24:99-101

3. Ahnefeld FW, Frey R, Fritsche P, Nolte H (1967) Die Glieder der Rettungskette. Munch Med Wochenschr. 109:2157-2161

4. Baskett $P$ (ed) (1989) Cardiopulmonary resuscitation. Monographs in Anaesthesiology 17:1-416 (Amsterdam, Elsevier)

5. Symposium (1961) Recent advances in emergency resuscitation. Md State Med J 10:398-411

6. Chamberlain D, Gattiker R, Hart N et al (1987) Report from a symposium: Recent achievements and present controversies in cardiopulmonary resuscitation. Eur Heart J 8:438-443

7. Chamberlain D (2005) Editorial: The International Liaison Committee on Resuscitation (ILCOR)-Past and present. Resuscitation 67:157-161

8. Holmberg S, Handley A, Bahr J et al (1992) Guidelines for basic life support: $s$ statement by the Basic Life Support Working Party of the European Resuscitation Council, 1992. Resuscitation 24:103-110

9. Chamberlain D, Bossaert L, Carli P et al (1992) Guidelines for advanced life support: A statement by the Advanced Life Support Working Party of the European Resuscitation Council, 1992. Resuscitation 24:111-121

10. Zideman D, Bingham R, Beattie T, et al. Guidelines for paediatric life support, a statement by the Paediatric Life Support Working Party of the European Resuscitation Council, 1993. Resuscitation 1994;27:91-105

11. Chamberlain D, Vincent R, Baskett P et al (1994) Peri-arrest arrhythmias (management of arrhythmias associated with cardiac arrest). A statement by the Advanced Life Support Committee of the European Resuscitation Council 1994. Resuscitation 28:151-159
12. Baskett $P$, Bossaert $L$, Carli $P$ et al (1996) Guidelines for the basic management of the airway and ventilation during resuscitation. Resuscitation 31:187-200

13. DickW (1998) Introduction: From ILCOR Policy Statements to ERC Model Guidelines. In: Bossaert L (ed) ERC Guidelines for Resuscitation. Elsevier Amsterdam, pp 1-217. ISBN 0444-82957-1

14. Nolan J (2005) European Resuscitation Council Guidelines for Resuscitation 2005. Introduction. Resuscitation 67:S3-S6

15. International Liaison Committee on Resuscitation ILCOR (2005) The 2005 International Consensus on Resuscitation and Emergency Cardiovascular care Science with treatment recommendations. Resuscitation 67:181-334

16. Nolan JP, Hazinski MF, Billi JE et al (2010) Executive summary: 2010 International Consensus on Cardiopulmonary Resuscitation and Emergency Cardiovascular Care Science with Treatment Recommendations. Resuscitation 81:e1-25

17. Arntz HR, Bossaert L, Carli P et al (1998) The prehospital management of acute heart attacks. Recommendations of a task force of the European Society for Cardiology and the European Resuscitation Council. Resuscitation 38:73-98

18. Priori S, Bossaert L, Chamberlain D et al (2004) Policy Statement: ESC-ERC recommendations for the use of automated external defibrillators (AEDs) in Europe. Eur Heart J 25:437-445

19. Nolan J, Neumar R, Adrie C et al (2008) Post-cardiac arrest syndrome: Epidemiology, pathophysiology, treatment, and prognostication. Resuscitation 79:350-379

20. DickW, Baskett P, Grande C et al (2000) Recommendations for uniform reporting of data following major trauma-the Utstein style. An International Trauma Anaesthesia and Critical Care Society (ITACCS) initiative. Br J Anaesth 84:818-819

21. Idris A, Becker L, Ornato J et al (1996) Utstein-style guidelines for uniform reporting of laboratory research. Circulation 94:2324-2336

22. Thies K, Gwinnutt C, Driscoll P et al (2007) The European Trauma Course-from concept to course. Resuscitation 74:135-141

23. Cummins RO, Chamberlain DA, Abramson NS et al (1991) Recommended guidelines for uniform reporting of data from out-of-hospital cardiac arrest: the Utstein style. A statement for health professionals from a task force of the American Heart Association, the European Resuscitation Council, the Heart and Stroke Foundation of Canada, and the Australian Resuscitation Council. Resuscitation 22:1-26

24. Jacobs I, Nadkarni V, Bahr J et al (2004) ILCOR Task Force on Cardiac Arrest and Cardiopulmonary Resuscitation Outcomes. Cardiac arrest and cardiopulmonary resuscitation outcome reports: update and simplification of the Utstein templates for resuscitation registries: a statement for healthcare professionals from a task force of the International Liaison Committee on Resuscitation. Resuscitation 63:233249

25. Gräsner JT, Herlitz J, Koster RW et al (2011) Quality management in resuscitation - towards a European cardiac arrest registry (EuReCa). Resuscitation 82:989-994

26. Declaration of the European Parliament of 14 June 2012 on establishing a European cardiac arrest awareness week http://www.europarl.europa.eu/ sides/getDoc.do?pubRef=-//EP//TEXT+TA+P7-TA2012-0266+0+DOC+XML+V0//EN\&language $=E N$. Accessed 20 September 2013 